\section{Histopathological and immunohistochemical study of the hepatic lesions experimentally induced by Entamoeba dispar}

\author{
C.A.X. Costa, ${ }^{1,3}$ K.N.O. Brito, ${ }^{1,3}$ \\ M.A. Gomes, ${ }^{2}$ M.V. Caliari ${ }^{3}$ \\ 'Programa de Pós-Graduação em \\ Patologia; 'Laboratório de Amebíase, \\ Departamento de Parasitologia; \\ ${ }^{3}$ Laboratório de Protozooses, \\ Departamento de Patologia Geral, \\ Instituto de Ciências Biológicas da \\ Universidade Federal de Minas Gerais, \\ Belo Horizonte, Minas Gerais, Brazil
}

\begin{abstract}
The sequence of hepatic necrotic-inflammatory events produced by Entamoeba dispar are originally described in this work. For the first time the experimental lesions produced by $E$. dispar were described in details, as well as the distribution of the trophozoites detected by the immunohistochemistry. Animals experimentally infected with $E$. dispar presented necrosis, thrombosis and chronic granulomatous inflammation. Immunoreactive products derived from trofozoites were observed close or associated with trophozoites, epithelioid cells, leucocytes and hepatocytes. Few are the articles on the literature about virulence of $E$. dispar, which is approximately 9 times more frequent than to Entamoeba histolytica ( $E$. histolytica). Variation in the virulence is therefore expected and signalizing the need of the continuity of studies with $E$. dispar strains from different places in the world. Taking into account that $E$. dispar is a closely related species to $E$. histolytica, these studies could determine new elements involved with $E$. histolytica pathogenesis, helping us to better understand the disease.
\end{abstract}

\section{Introduction}

Entamoeba histolytica (E. histolytica) is a protozoan, which causes amebiasis. It infects approximately $10 \%$ of people all over the world and causes about 100 thousand deaths per year; it is considered the second most common cause of mortality by protozooses. ${ }^{1}$ E. histolytica resides at the lower intestine, but can occasionally invade the intestinal mucosa and, through blood, disseminate to other organs. The factors that trigger this invasion are still not completely understood. The intestinal infection varies from asymptomatic colonization to serious invasive infections with bleeding diarrhea. The most common site for extraintestinal disease is the liver, where $E$. histolytica causes slow expanding necrosis (amoebic liver abscess), but can also occur in the diaphragm and right lung because of contiguity with the hepatic lesion; in the left lung, brain and pericardium by the hematogenous route.

In spite of the great number of deaths for the disease, most of those infected are asymptomatic. In this context, the existence of another species could explain the asymptomatic cases; $E$. dispar is the name given to this species. ${ }^{2}$ The data accumulated along the 80's gave us support to the existence of the $E$. dispar. $^{3-6}$ In 1997, the World Health Organization admitted the existence of $E$. dispar as a noninvasive entity, morphologically similar to $E$. histolytica, but not able to cause amebiasis. This ameba is responsible for the majority of asymptomatic infections previously attributed to $E$. histolytica and can only produce erosions in the intestinal mucosae of experimental animal. ${ }^{7}$ Little is known about this new species at the virulence level for experimental animals, since the majority of the cultivated strains do not present infective capacity. Preliminary results, obtained in our laboratory, have shown that $E$. dispar isolated from asymptomatic patients and clinical cases of non-dysenteric colitis produced hepatic and intestinal lesions in hamsters (Mesocrisetus auratus), similar to those produced by $E$. histolytica isolated from symptomatic ones patients. ${ }^{8-11}$ Hepatic and intestinal lesions were also produced in wistar rats and swiss mice through inoculation of $E$. dispar (unpublished data).

In a previous work, hamsters also developed hepatic lesions quantitatively and qualitatively similar to those induced by $E$. histolytica. ${ }^{12}$ In addition, a gradual decrease was observed in the number of trophozoites in the course of infection. The decrease of trophozoites number associated with progressive increase of necrosis during inflammatory kinetics suggested that trophozoites destruction could promote the consequent release of toxic products that would contribute to the increase of necrosis. Here, we study the pathogenicity of one $E$. dispar strain by histopathological analysis in different periods of the infection of hamster liver, following the trophozoites through immunohistochemistry.

\section{Materials and Methods}

\section{Strains and culture conditions}

The MCR strain was isolated from an
Correspondence: Dr. M.V. Caliari, Departamento de Patologia Geral, Instituto de Ciências Biológicas, Universidade Federal de Minas Gerais, Av. Antônio Carlos 6627, Belo Horizonte, Minas Gerais, Brazil, CEP 31.270.901.

Tel.+55.31.3409.2892 - Fax:+55.31.3409.2879. E-mail: caliari@icb.ufmg.br

Key words: Entamoeba dispar, hepatic necrosis, granuloma, pathogenicity.

Aknowledgements: this work was supported by FAPEMIG (Fundação de Amparo à Pesquisa de Minas Gerais) and CNPq (Conselho Nacional de Desenvolvimento Científico e Tecnológico). The authors are grateful to Gislene Arlindo da Silva, Olinda Disidéria Rodrigues and Edna Maria Pires for the technical assistance, and Carolina Dias for the English review of this manuscript.

Received for publication: 1 May 2010.

Accepted for publication: 14 July 2010.

This work is licensed under a Creative Commons Attribution 3.0 License (by-nc 3.0).

(C) Copyright C.A.X. Costa et al., 2010

Licensee PAGEPress, Italy

European Journal of Histochemistry 2010; 54:e39 doi:10.4081/ejh.2010.e39

asymptomatic carrier residing in Manaus, Amazonas, Brazil with negative serology for $E$. histolytica. Stool microscopic examination showed, beyond amoebae, yeast and Blastocystis. Miconalzole was used to eliminate Blastocystis and yeast, which could affect the amoeba's growth in the culture. ${ }^{13}$

MCR showed the pattern I of isoenzyme, typical of $E$. dispar species. ${ }^{14}$ The use of specific probes to amplify regions of rDNA from $E$. histolyticalE. dispar complex also identified the sample as E. dispar. ${ }^{15}$ Trophozoites were grown in Pavlova's medium modified by Silva and Mayrink $^{16}$ at $37^{\circ} \mathrm{C}$, and subcultured three times a week. One $E$. histolytica strain was used as control.

\section{Inoculation}

All procedures were conducted in accordance to the Brazilian College of Animal Experimentation, registered by number: CETEA 007/04. Twenty-five hamsters Mesocricetus auratus - were inoculated via intra-hepatic route (in the left lobe) with $E$. dispar MCR strain. Inocula consisted of 100,000 trophozoites in $0.1 \mathrm{~mL}$ of saline. Three animals were inoculated with the flora of the strain in order to control the possibility of bacterial lesions formation.

\section{Necropsy and histopathology}

The animals were observed daily and groups 
of five animals were necropsied in the 1st, 2 nd, $3^{\text {rd }}, 6^{\text {th }}$ and $8^{\text {th }}$ day after inoculation. All the animals inoculated with the flora were sacrificed at and after infection. Liver fragments were collected and fixed in 10\% buffered formaldehyde $\mathrm{pH}$ 7.2. After processing in alcohol and xylol, fragments were included in paraffin and $4 \mu \mathrm{m}$ thick sections were obtained and stained by haematoxylin and eosin (H\&E).

\section{Preparation of antigenic pools of $E$. dispar}

Trophozoites of $E$. dispar were cultivated in bottles containing Pavlova media at $37^{\circ} \mathrm{C}$. The cultures were then washed 6 times with a buffered saline solution at 2,000 xg. The trophozoites pellets were treated with protease inhibitors ( $2 \mathrm{mM}$ phenylmethyl chloromethyl ketone; $2 \mathrm{mM}$ iodoacetamide and $2 \mathrm{mM}$ hydroxy mercuribenzoate), and then ultrasonicated (frequency of 40 hertz) three times for 1 min. The protein content of the homogenate was determined by Lowry method and stored at $-20^{\circ} \mathrm{C}^{17}$

\section{Obtaining immune serum}

Two rats were inoculated intraperitoneally with $5 \times 10^{6}$ trophozoites of the MCR strain. Fifteen days later, $5 \mathrm{mg}$ of homogenate MCR, previously emulsified in Freud's complete adjuvant, was subcutaneously administered. Ten days later, the blood was collected after a thoracic opening and sera were separated and stored at $-20^{\circ} \mathrm{C}$. ELISA tests were performed to evaluate the specificity of antisera against antigens of $E$. dispar.

\section{Immunohistochemistry}

Using the same tissue fragments already mentioned, streptoavidin-peroxidase immunohistochemical reactions for detection of trophozoites were performed. Sections were treated with $3.5 \% \mathrm{PBS} / \mathrm{H}_{2} \mathrm{O}_{2}$ solution for blocking endogenous peroxidase. Unspecific binding was blocked by goat serum diluted 1:50. The sections were incubated with anti- $E$. dispar serum diluted 1:2000, followed by biotinylated goat IgG diluted 1:100 (Zymed Laboratories Inc., San Francisco, CA, USA) and streptavidin diluted 1:100 (Zymed Laboratories Inc.). The color was detected using a $0.05 \%$ diaminobenzidine solution and $0.2 \% \mathrm{H}_{2} \mathrm{O}_{2}$ and the sections were counterstained with diluted Harris's haematoxylin. Primary antiserum was substituted by PBS in some sections for negative control purposes. Sections were qualitatively analyzed in an attempt to evaluate the presence and the distribution of the trophozoites in relation to the lesions.

\section{Results}

\section{Histopathological analyses}

Amoebic hepatic lesions were macroscopically detected in almost all the animals inoculated with $E$. dispar. Twenty-four hours after infection the lesion was visible at the left lobe; it was single, white-yellowish colored and well delimited. A histopathological description in the different periods of infection is shown below. The frequency of some alterations is listed in Table 1.

\section{$1^{\text {st }}$ day after inoculation}

Single necrosis zone, well delimited by clumping of cell debris and by normal hepatic parenchyma was observed (Figure 1a). Inflammatory infiltrate was discrete and mixed, constituted by neutrophils and macrophages. In one animal, two large necrosis zones were observed. The center was constituted of coagulation necrosis and a few calcification zones. A large number of labeled trophozoites were found on the edges of the lesion in two animals of this group. The parasites were found next to lesioned and normal hepatocytes, as well as inflammatory cells. In these cells positive reactions were also found, indicating the presence of material derived from trophozoites. In another animal, a centerlobular vein showing initial thrombosis was found next to a necrosis zone (Figure 1a).

\section{$2^{\text {nd }}$ day after inoculation}

In all animals, at least one central necrosis zone was observed. The necrosis was well delimited by debris, discrete to moderate inflammatory infiltrate and large number of trophozoites (Figure 1b). Several labeling products of $E$. dispar were found on the surface and inside host's cells. A variable number of granulomas containing epithelioid cells and rare giant cells were found (Figures 1c, d). Most of them had either morphologically well preserved or destroyed trophozoites. In one animal three thrombi were observed in branches of the portal vein. They also had trophozoites on the wall and in the vascular lumen, as well as inside the thrombus (Figure $1 \mathrm{e}, \mathrm{f})$. A great number of hepatocytes and leucocytes with suggestive morphologic features of apoptosis (cell shrinkage and chromatin condensation into crescentic masses adjacent to nuclear membrane) were found at the border of the central necrosis zone, as well as in the granulomas.

\section{$3^{\text {rd }}$ day after inoculation}

In three animals granulation tissue occupied most of the destroyed hepatic parenchyma, associated to the predominantly mononuclear inflammatory infiltrate. Numerous granulomas, constituted by a great number of epithelioid cells, macrophages, few lymphocytes and frequent trophozoites were detected in these animals. In the remaining two animals the predominant histopathological aspect was an intense liquefactive necrosis delimited by a large amount of debris, scarce leukocytes and variable number of trophozoites. $E$. dispar anti-trophozoite immunohistochemistry labeling reaction products were mainly found on the surface of leucocytes. Morphological signs of hepatocyte apoptosis close to the infiltrate were frequent (Figure 2).

\section{$6^{\text {th }}$ day after inoculation}

The border of necrosis zones was constituted by palisades of macrophages; this layer was totally involved by well developed granulation tissue and granulomas. Several giant cells were found in this region. These granulomas had a large number of epithelioid cells, macrophages, debris, and frequently, trophozoites. Antitrophozoite immunohistochemistry labeling products were always observed close or associated with trophozoites, leucocytes and hepatocytes, inside necrosis zones, on its border and inside granulomas (Figure 3a).

\section{$8^{\text {th }}$ day after inoculation}

Three different histopathological aspects were observed in this group. In two animals numerous and very well organized granulomas were found (Figure 3b, c, d). Externally, granulomas were constituted by a sheath of concen-

Table 1. Qualitative and quantitative aspects of the hepatic lesions and trophozoites of $E$. dispar.

\begin{tabular}{|c|c|c|c|c|c|c|c|}
\hline & $\begin{array}{c}\text { Trophozoites } \\
\text { (1) }\end{array}$ & $\begin{array}{l}\text { Intravascular I } \\
\text { trophozoites (2) }\end{array}$ & $\begin{array}{l}\text { Immunoreactiv } \\
\text { products (3) }\end{array}$ & $\begin{array}{l}\text { anula } \\
\text { tissue }\end{array}$ & ibros & $0 \mathrm{mb}$ & anulome \\
\hline $1^{0}$ & $* 2 / 5$ & $0 / 5$ & $1 / 5$ & $0 / 5$ & $0 / 5$ & $1 / 5$ & $0 / 5$ \\
\hline $2^{0}$ & $4 / 5$ & $1 / 5$ & $4 / 5$ & $4 / 5$ & $0 / 5$ & $1 / 5$ & $4 / 5$ \\
\hline $3^{0}$ & $3 / 5$ & $0 / 5$ & $2 / 5$ & $5 / 5$ & $0 / 5$ & $1 / 5$ & $3 / 5$ \\
\hline $6^{0}$ & $3 / 5$ & $1 / 5$ & $3 / 5$ & $5 / 5$ & $0 / 5$ & $2 / 5$ & $3 / 5$ \\
\hline $8^{\circ}$ & $2 / 5$ & $0 / 5$ & $2 / 5$ & $5 / 5$ & $2 / 5$ & $0 / 5$ & $5 / 5$ \\
\hline
\end{tabular}

*The frequency of the lesions and of the trophozoites/immunoreactive products are demonstrated in the proportion: number of positive animals/5 animals of the experimental group. (1) Presence of trophozoites in the normal and necrotic hepatic tissue. (2) Presence of trophozoites in vascular lumen or inside thrombi. (3) Positivity for immunoreactive products derived of trophozoites in the necrosis areas, around or inside hepatocytes and inflammatory cells. 
trically arranged macrophages, lymphocytes and neutrophils. The next layer was constituted by a thick clump of well compacted macrophages and epithelioid cells. The central region of the granuloma was constituted by a variable number of epithelioid cells, macrophages, neutrophils, trophozoites and necrosis. In other two animals necrosis zones were not observed. The whole destroyed region was substituted by granulation tissue, which partly evolved to fibrosis zones. Granulomas and a significant number of giant cells were also observed. Granulomas were quite smaller than those described in the two previous animals, with predominance of lymphocytes, followed by epithelioid cells and macrophages. Around the granulomas diffuse mononuclear inflammatory infiltrate was observed. In the remaining animal a condition identical to that described for the $6^{\text {th }}$ day was observed.

\section{Hamsters inoculated with the flora of MCR strain}

In all animals macro or microscopic lesions were not observed.

\section{Discussion}

Some authors compared the pathogenesis of $E$. dispar with that of $E$. histolytica by inducing hepatic lesions in hamsters through inoculation of $E$. dispar axenic strain. ${ }^{18}$ Seven days after inoculation there was an intense inflammatory infiltration constituted by macrophages, lymphocytes and some giant cells. No granulomas, necrosis zones nor trophozoites were found. In contrast, we observed hepatic necrosis in almost all animals inoculated with $E$. dispar, except for two animals in which zones of destruction had been completely substituted by granulation tissue and fibrosis. Also, different from the study above cited, the histopathological condition promoted by $E$. dispar in our experiment was similar to that produced by $E$. histolytica, including the development of granulomas after the $2^{\text {nd }}$ day of infection.

Amomg the 25 animals inoculated with $E$. dispar, 14 had trophozoites in the hepatic parenchyma. There was no doubt about the identity of the parasite, since $E$. dispar strain was previously identified by zymodeme and PCR. E. dispar trophozoites were found especially on the border of the lesion and inside necrosis zones, as described in the literature in relation to $E$. histolytica. ${ }^{19,20}$ Similarly to what was described by other authors in relation to the infection produced by $E$. histolytica, the presence of small granulomas constituted of macrophages, epithelioid cells and giant cells in the animals inoculated with $E$. dispar
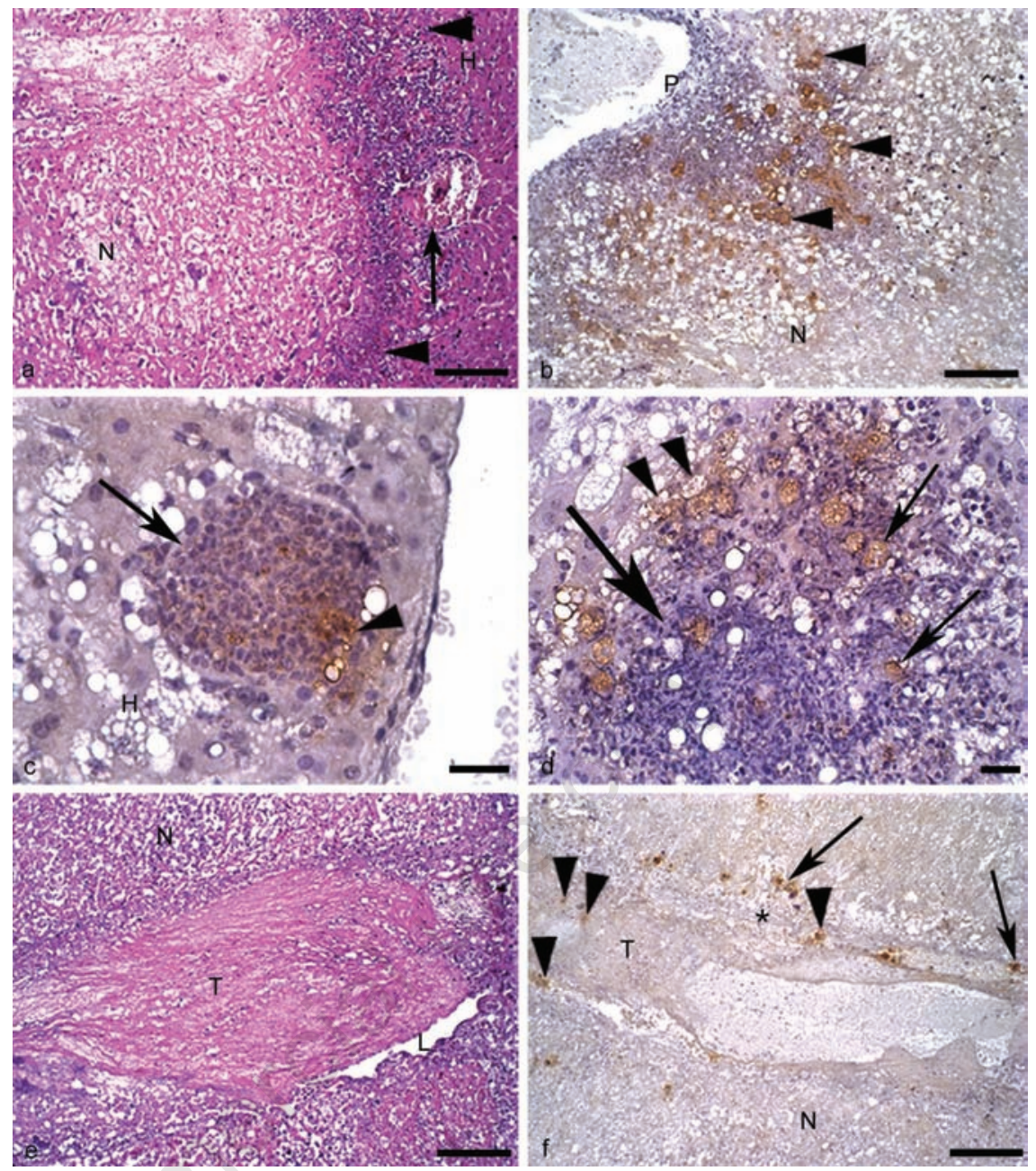

Figure 1. Hamster liver inoculated with $E$. dispar. H\&E and immunohistochemistry for E. dispar trophozoites, haematoxylin counterstained. (a) $1^{\text {st }}$ day of infection. Necrosis $(\mathrm{N})$; normal hepatic tissue (H); cell debris and scarce leucocytes (arrowheads); blood vessel partially obstructed by a thrombus (arrow). Bar $100 \mu \mathrm{m}$. H\&E. (b) $2^{\text {nd }}$ day of infection. Portal tract $(P)$; numerous positive trophozoites for antigens of $E$. dispar (arrowheads); necrosis $(\mathrm{N})$. Bar $100 \mu \mathrm{m}$. (c) $2^{\text {nd }}$ day of infection. Granuloma rich in epithelioid cells (arrow) surrounded by degenerated hepatic tissue $(\mathrm{H})$; note the positive reaction for E. dispar antigens inside the granuloma (arrowhead). Bar $20 \mu \mathrm{m}$. (d) $2^{\text {nd }}$ day of infection. Granuloma constituted by epithelioid cells, macrophages and scarce lymphocytes (big arrow); stained trophozoites inside and close to the granuloma (arrows); positive immunohistochemistry reaction for $E$. dispar antigens inside vacuolated trophozoites (arrowheads). Bar $20 \mu \mathrm{m}$. (e) $2^{\text {nd }}$ day of infection. Thrombus (T) almost totally occluding a branch of the portal vein; vascular lumen $(\mathrm{L})$; necrosis of hepatic tissue $(\mathrm{N})$. Bar $100 \mu \mathrm{m}$. H\&E. (f) $2^{\text {nd }}$ day of infection. Vascular wall $(*)$; thrombus (T); stained trophozoites inside the thrombus (arrowheads) and close to the vascular wall (arrows); necrosis of hepatic tissue (N). Bar $100 \mu \mathrm{m}$.

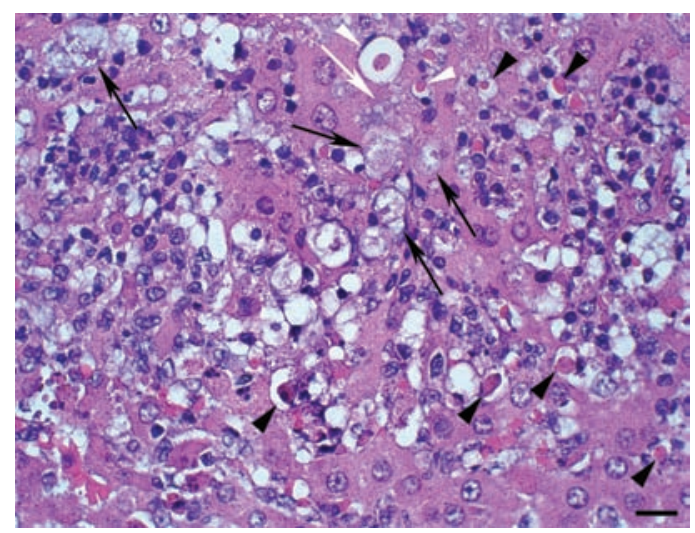

Figure 2. Hamster liver inoculated with $E$. dispar ( $3^{\text {rd }}$ day of infection) H\&E. Hepatocytes show round shape, condensation of chromatin and cell shrinkage (arrowheads); trophozoites (arrows); note the presence of a trophozoite (white arrow) in close contact with hepatocyte shrinkage (white arrowheads). Bar $20 \mu \mathrm{m}$. 
were frequent in the $2^{\text {nd }}$ day of infection. ${ }^{20}$ This condition was more intense with time after inoculation, forming well-defined granulomas, until larger areas of necrosis were involved by palisades of macrophages and epithelioid cells. Formation of granulomas in amebiasis has also been reported in other experimental models, such as intestinal granulomas, which also appear at the $2^{\text {nd }}$ day after infection in normal and neutropenic rats. ${ }^{21}$ However, the pathogenetic mechanisms responsible for this, as well as the antigens and cytokines involved are totally unknown. Some granulomas produced by $E$. histolytica and documented in the literature are identical to those we observed in the animals inoculated with $E$. dispar. Immuno histochemical identification of several $E$. dispar trophozoites inside many granulomas makes it clear that the protozoon participates in their genesis.

A higher number of hepatocytes with cell shrinkage and chromatin condensation into crescentic masses adjacent to nuclear membrane were observed in the $3^{\text {rd }}$ day, with a visible reduction occurring at the $6^{\text {th }}$ and $8^{\text {th }}$ days after infection. Non-classic apoptosis mechanisms seem to be induced by $E$. histolytica. ${ }^{22}$ This ameba is capable of inducing apoptosis even when there is over-expression of the Bcl2 protein, absence of activation via Fas/Fas ligand and the TNF- $\alpha$ receptor. Based on these findings, it has been suggested that $E$. histolytica induces apoptosis by directly activating the distal apoptotic machinery of the host's cells. In the same study, the authors were able to significantly reduce the apoptotic indices in the intestinal epithelium of mice through utilization of D-galactose suggesting the involvement of amoebic galactose/N-acetyl-D-galactosamine (Gal/GalNAc) lectin. Although $E$. histolytica and $E$. dispar share a high homology for this lectin, we cannot affirm that E.dispar is able to induce apoptosis. The $E$. dispar inability to destroy MDCK cells in vitro does not allow to evaluate the D-galactose effect on the inhibition of Ga/GalNAc lectin. ${ }^{23}$ The mediators released by inflammatory cells could have produce apoptosis. Further studies with more direct methodologies would be necessary to study this type of cellular death in animals inoculated with $E$. dispar.

Some molecules related to pathogenic functions in E. histolytica are present in E. dispar, but in small quantity or they are less active, which could suggest the possibility of evolution of $E$. histolytica to a less aggressive form: E. dispar. ${ }^{5,24,25}$ Another possibility refers to intrinsic variability of this own species to promote the tecidual destruction by some strains like that we have already observed. Indeed, $\mathrm{Balb} / \mathrm{C}$ mice inoculated with the $E$. dispar strain ADO showed significantly greater num-

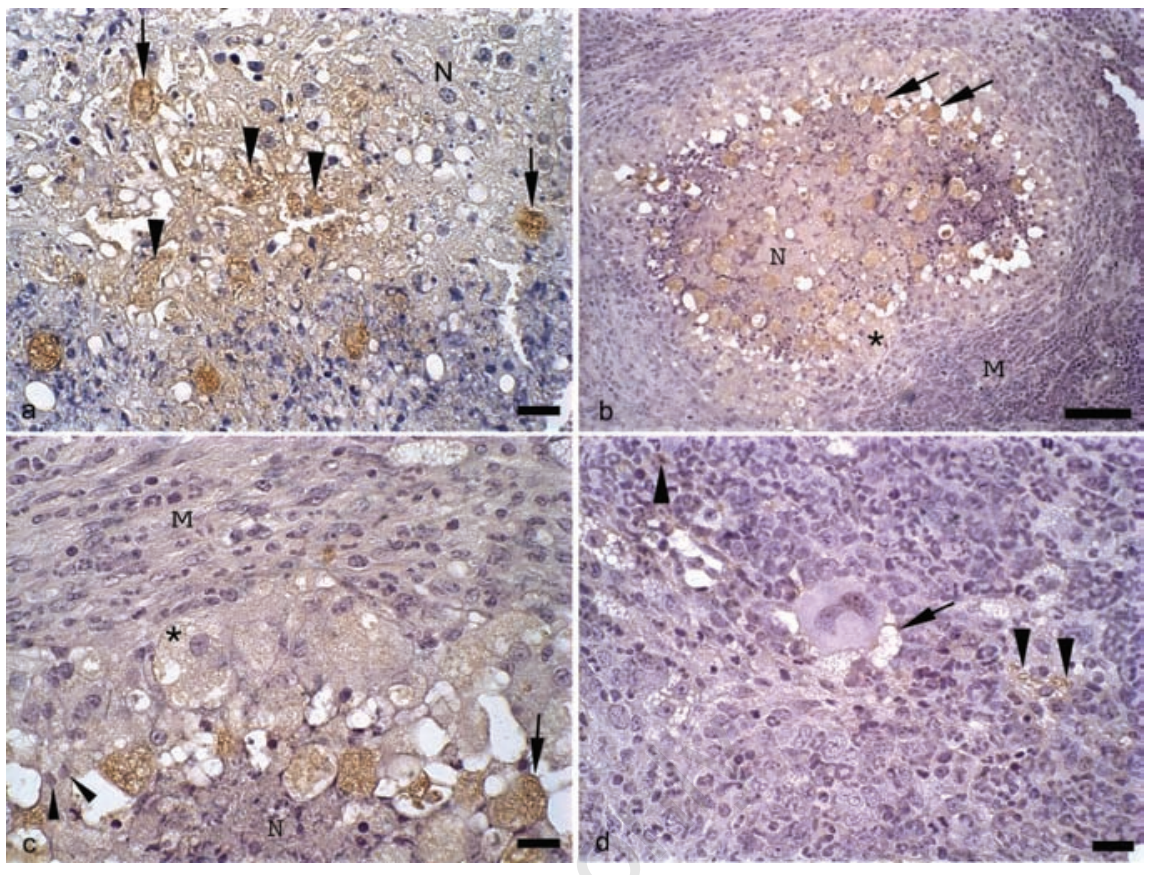

Figure 3. Hamster liver inoculated with $E$. dispar. and immunohistochemistry for $E$. dispar trophozoites, haematoxylin counterstained. (a) $6^{\text {th }}$ day of infection. Presence of trophozoites (arrows) in area of hepatic necrosis $(\mathrm{N})$; positive immunohistochemistry reaction for $E$. dispar antigens inside necrotic hepatocytes (arrowheads). Bar $20 \mu \mathrm{m}$. (b) $8^{\text {th }}$ day of infection. Granuloma with area of central necrosis $(\mathrm{N})$ and several stained trophozoites (arrows); well compacted macrophages and epithelioid cells $(*)$; mantle of concentrically arranged macrophages, lymphocytes and neutrophils $(M)$. Bar $100 \mu \mathrm{m}$. (c) Higher view of the anterior figure showing foam macrophages with positive cytoplasmatic labeling for $\boldsymbol{E}$. dispar antigens $(*)$; epithelioid cells (arrow heads); trophozoite (arrow); mantle of macrophages, lymphocytes and neutrophils $(\mathrm{M})$; necrosis $(\mathrm{N})$. Bar $20 \mu \mathrm{m}$. (d) $8^{\text {th }}$ day of infection. Detail of a mantle of macrophages, lymphocytes and neutrophils; note the positive reaction for $E$. dispar antigens inside inflammatory cells (arrowheads) and close to a Langhans-type giant cell (arrow). Bar $20 \mu \mathrm{m}$.

ber of trophozoites and greater amount of nodular lesions than those observed in mice inoculated with the $E$. dispar strain VEJ. ${ }^{26}$ In this experiment, the first group of animals also showed a larger necrosis area and an increase of trophozoites antigens tagged by immunohistochemistry, although a statistically significant difference was not verified (unpublished data). In this context, some $E$. dispar strains could have shown higher virulent potential. The absence of necrosis induced by inoculation of the flora that accompanies the strain, nullifies the possibility that bacteria produced the lesions.

Our results suggest the necessity of studying other strains of $E$. dispar isolated from different places in the world to prove and realize the variation in the virulence of this species. Taking into account that $E$. dispar is a closely related species to $E$. histolytica, these studies could determine new elements involved with $E$. histolytica pathogenesis, helping us to better understand the disease.

\section{References}

1. Stanley SL Jr. Amoebiasis. Lancet 2003; 361:1025-1034.

2. Brumpt E. Etude sommaire de I'Entamoeba dispar n.sp. amibe akkystes quadrinuclees, parasite de I'homme. Bull Acad Méd Paris 1925;94:942-52.

3. Diamond LS. Amebiasis: a problem solved: What now? Arch Med Res 1992;23:157-16.

4. Diamond LS, Clarck CG. A redescription of Entamoeba histolytica Schaudinn, 1903 (Emended Walker, 1911) separating it from Entamoeba dispar Brumpt, 1925. J Eukaryot Microbiol 1993;40:340-4.

5. Dodson JM, Clark CG, Lockhart LA, Schroeder JW, Mann BJ. Comparison of adherence, cytotoxicity, and $\mathrm{Gal} / \mathrm{GalNac}$ lectin gene struture in Entamoeba histolityca and Entamoeba dispar. Parasitol Int 1997;46:225-235.

6. Sargeaunt PG, Willians JE, Neal RA. A 
Comparative study of Entamoeba histolytica (NIH 200, HK9), "E. histolytica like" and other morphologically identical amoeba using isoenzyme eletrophoresis. T Roy Soc Trop Med H 1980;74:469-474.

7. World Health Organization. Weekly epidemiological record Geneva 1997;72:97100.

8. Costa A0, Viana JC, Assis D, Rocha OA, Silva EF. Comparation of Xenic and Monoxenic Entamoeba dispar cultures using hepatic inoculation in hamster. Arch Med Res 2000;31:247-8.

9. Furst C, Gomes MA, Tafuri WL, Silva EF. Biological aspects of a brazilian strain of Entamoeba dispar. Pathologica 2002;94: 22-7.

10. Gomes MA, Melo MN, Macedo AM, Pena GP, Caliari MV, Silva EF. Characterization of Entamoeba histolytica and Entamoeba dispar by biological, and Molecular Parameters. Arch Med Res 2000;31:249-50.

11. Shibayama M, Dolabella SS, Silva EF, Tsutsumi V. A Brazilian species of Entamoeba dispar (AD0) produces amoebic liver abscess in hamsters. Ann Hepatol 2007;6:117-18.

12. Costa CA, Brito KN, Gomes MA, Caliari MV. Morphometric study of the hepatic lesions experimentally induced in hamsters by Entamoeba dispar and E. histolytica. Parasite 2007;14:329-34.

13. Gonçalves AQ, Viana Jda C, Pires EM, Bóia MN, Coura JR, Silva EF. The use of antifun- gal agent miconazole as an inhibitor of Blastocystis hominis growth in Entamoeba histolytica/E. dispar cultures. Rev Inst Med Trop Sao Paulo 2007;49:201-2.

14. de Martinez AM, Gomes MA, Viana Jda C, Romanha AJ, Silva EF. Isoenzyme profile as parameter to differentiate pathogenic strains of Entamoeba histolytica in Brazil. Rev Inst Med Trop Sao Paulo 1996;38:407-12.

15. Gomes MA, Pesquero JB, Furst C, Valle PR, Pesquero JL, Silva EF. An improved method to distinguish Entamoeba histolytica and E. dispar. Parasitology 1999;119:359-62.

16. Félix-Silva E, Mayrink W. Estudo sobre a Entamoeba moshkowskii II. Novos focos em diversos tipos de coleções hídricas no Brasil e Uruguai. Rev Inst Med Trop Sao Paulo 1974;16:203-21.

17. Lowry $\mathrm{OH}$, Rosebrough $\mathrm{NJ}$, Farr AL, Randall RJ. Protein measurement with the Folin phenol reagent. J Biol Chem 1951;193:265-75.

18. Espinosa Cantellano M, Castañón Gutiérrez G, Martínez-Palomo A. In vivo pathogenesis of Entamoeba dispar. Arch Med Res 1997;28:204-6.

19. Shibayama M, Campos-Rodrigues R, Ramirez-Rosales A, Flores-Romo L, Espinosa-Cantellano M, Martínez-Palomo A, et al. Entamoeba histolytica: Liver invasion and abscess producion by intraperitoneal inoculation of trophozoites in hamsters, Mesocricetus auratus. Exp Parasitol 1998;88:20-27.
20. Tsutsumi V, Mena-Lopez R, AnayaVelazquez F, Martínez-Palomo A. Cellular bases of the experimental amebic liver abcess formation. Am J Pathol 1984;117: 81-91.

21. Rivero-Nava L, Aguirre-Garcia J, Shibayama-Salas M, Hernández-Pando R, Tsutsumi V, Calderón J. Entamoeba histolytica: acute granulomatous intestinal lesions in normal and neutrophil-depleted mice. Exp Parasitol 2002;101:183-92.

22. Huston CD, Houpt ER, Mann BJ, Hahn CS, Petri WA Jr. Caspase-3 dependent killing of host cells by the parasite Entamoeba histolytica. Cell Microbiol 2000;2:617-25.

23. Brito KNO, Costa JO, Viana JC, Gomes MA, Caliari MV. Avaliação da função da lectina GAL/GALNac em Entamoeba dispar. Anais do XX Congresso Brasileiro de Parasitologia 2007, Olinda, Brasil.

24. Leippe M. Amoebapores. Parasitol Today 1997;13:178-83.

25. Que X, Reed SL. Cysteine proteinases and the pathogenesis of amebiasis. Clin Microbiol Rev 2000;13:196-206.

26. Brito KNO, Viana JC, Gomes MA, Caliari MV. Avaliação da patogenicidade de cepas polixênicas de Entamoeba dispar em comparação com polixênica e axênica de Entamoeba histolytica em camundongos Balb-c. Anais do XX Congresso Brasileiro de Parasitologia 2007, Olinda, Brasil. 